\title{
1
}

\section{Public policy theory, practice and teaching: Investigating the interactions}

\author{
Trish Mercer, Russell Ayres, Brian Head \\ and John Wanna
}

\begin{abstract}
In theory, there is no difference between theory and practice. But, in practice, there is. (Eigen quoted in Nature Neuroscience, 2005, p. 1627)
\end{abstract}

\section{Why investigate these interactions?}

This book grew out of a longstanding interest in examining the perceived disconnects between the theory and the practice of policymaking to discover whether insights drawn from theories of the policy process could be-and indeed have been and are being_employed by academics, public servants and practitioner academics. Although real world policymaking is essentially a practical activity, involving government and non-government actors, there have been myriad attempts to construct theory-informed explanations of such practices to better understand their logics. These presumed linkages might arise in many contexts and temporal dimensions, from attempting to analyse past policy episodes through to practical applications in the pressure cooker environment of working within government organisations. 
Distilling the myriad issues involved, we see two main problems: practitioners do not see academic insights as directly useful to their policy activities, and theorists tend to write for other scholars and to contribute to existing debates in the literature. While the contrast may be overdrawn, bureaucrats are more interested in solutions while academics are motivated by attempts to define and delineate the problems. The challenge is to see these two perspectives as more synergistic than antagonistic.

The language employed in theories about the making of policy tends to be self-referential, obtuse and dense, studded with conceptual jargon and references to other bodies of theory. From the 1950s and more recently, however, some theories have been developed with a greater focus on practical applications. Some of this theorising is underpinned by normative concepts including rational decision-making, public choice, public value, public integrity and accountability. The development and application of policy theory for practical purposes is indeed a burgeoning field of academic analysis, with policy theorists seeking to translate the insights from complex theoretical constructs to present more immediate value for policymakers and practitioners (Cairney 2015; Cairney \& Weible 2017). Some theories are intentionally pitched at a broad or meta level, while others are tackled more narrowly through a case study orientation focused on policy in action.

Yet, the impact of such theories and concepts on the work of practitioners and policymakers has been a largely neglected area of research and analysis. This book seeks to help redress this gap in the literature. To be sure, policy theory has been utilised in particular case studies that can be readily located in the Australian and New Zealand literature; usually the authors are academics and occasionally practitioner academics. There have also been two recent volumes that were deliberately centred upon a particular theoretical approach. The first was a collection edited by Katherine Daniell and Adrian Kay (2017) that examined the concept of multi-level governance and its explanatory power for Australian public policy. This volume included both conceptual chapters (written largely by academics) and case study chapters ranging across social and environmental policy domains (written by practitioner academics). ${ }^{1}$ The second was a collection of case studies of successful public policy in Australia and New Zealand, edited by Joannah Luetjens, Michael Mintrom and Paul 't Hart (2019a).

1 The theory and practice of multi-level governance has also been extensively developed and researched in the European Union. 
This volume outlined a 'policy success assessment map' drawing on academic research into success that the contributing authors used as a template to analyse a diverse and detailed set of policy cases.

This present volume of essays strikes out in a different direction. There is no singular theoretical approach that informs the collection; indeed, we recognise that there are many important policy theories that are not discussed or mentioned only in passing. There are excellent standard texts that outline the wider spectrum of theoretical approaches to policy study, such as Christopher Weible and Paul Sabatier's Theories of the policy process (2017 and earlier editions) and Paul Cairney's Understanding public policy (2020). Rather, our primary intent is to offer some practical insights from those who research and teach in policy studies, and from those involved in the practices of policy development and implementation, in relation to how public policy theories are presented to individual public servants (practitioners), what we know about how teaching experiences impact on practice, and, conversely, how policy practices influence academic teaching and research.

\section{Policymaking capacity- the interconnections}

We see this issue as highly relevant to the issue of policymaking capacity. Since the 1990s, leading politicians, academics and informed commentators have persistently complained about the weak policy capacity of public servants and their departments. This critical judgement about the alleged declining capacity of the public service has also been echoed in international literature across Westminster-style political systems such as the United Kingdom, New Zealand and Canada (Parsons 2004, p. 45; Tiernan 2011, pp. 335, 337). The waves of public sector reforms through the 1980s and 1990s, commonly described as new public management (NPM), resulted not only in the public sector downsizing selected functions and outsourcing its service delivery, but also in the increasing contestability of policy advice to ministers. Governments increasingly obtained policy advice from diverse sources including ministerial advisory staff, consultancy firms and think tanks (Head 2015, p. 54). 
Some see claims of declining policy capacity in the Australian Public Service (APS) as lacking an empirical basis or even as the product of 'rumour', as suggested by Janine O'Flynn et al. (2011, p. 310). This 'declinist' discourse concerning public service capability in the contemporary era has also been challenged in recent positive case studies of 'standout public policy accomplishments' in Australia and New Zealand (Luetjens, Mintrom \& 't Hart 2019b, p. 3). The truth of the matter is likely to be variable between and within public services, with strong capacity in some departments and agencies and weak capacity in others, as suggested by the Australian Public Service Commission's (APSC) capability reviews (discussed below).

Complaints about policy capacity are particularly associated with the arrival of new governments that have ambitious new policy agendas. In Australia, new ministers in John Howard's Coalition government in 1996 and again in the Rudd Labor government in 2007 were critical of the APS's slow response to their big agendas. Prime Minister Kevin Rudd and the new secretary of his department, Terry Moran, communicated 'a trenchant critique' of the APS, and Moran was tasked with chairing an expert advisory group to develop the blueprint for a world-class public service (Lindquist 2010, pp. 117-18). While our discussion here largely relates to the federal level of government, similar critiques have been made across jurisdictions at the state government level (and in many local government contexts as well).

The report of the Moran advisory group (Ahead of the game) identified 'enhancing policy capacity' as a key priority (Advisory Group on Reform of Australian Government Administration 2010, p. ix). The departmental capability reviews recommended in the report, and subsequently coordinated by the APSC in several key departments between 2012 and 2015, also drew attention to weaknesses in strategic policy expertise (e.g. see Australian Government 2013, pp. 209-10). These concerns persist in contemporary debates and discourse: less than a decade after Ahead of the game, then Prime Minister Malcolm Turnbull established yet another inquiry - hailed as an independent review of the capability, culture and operating model of the APS, and chaired by David Thodey (CSIRO chair and former CEO of Telstra). Its interim report (Priorities for change) highlighted concerns that the APS's underlying policy capacity had been weakened over time (Commonwealth of Australia 2019, p. 15). 
Whatever the actual situation, the perception of a decline in policy capacity is frequently raised as a concern, and made a focus for future improvement. Even before the finalisation of Thodey's Independent review of the APS, the APS Secretaries Board was galvanised into addressing policy advising weaknesses, with a cross-agency policy capability project producing an insightful APS policy capability roadmap in March 2019, built on feedback received across the APS and beyond (Australian Government 2019; Easton 2019a). By November 2019, however, with the Coalition government having recently been returned under Prime Minister Morrison, and with a new secretary for the Department of Prime Minister and Cabinet (PM\&C), Philip Gaetjens, the APS's project launch was something of a damp squib: its earlier promise of a 'common policy model' had become a simplified and loose framework consisting of four 'key elements' for delivering great policy, with a policy hub website providing more detail and resources. Further undermining this effort, most of the initiative's secretary-level 'champions' lost their jobs in a major machinery-of-government revamp of the APS. ${ }^{2}$

Under the Morrison government, concern about the policy capacity of its bureaucrats appears to have slipped in priority. The government's underwhelming response to the final report of the Independent review of the APS was released in December 2019. The response document, Delivering for Australians, reinforced the prime minister's strong view, earlier expressed in his annual address to the APS, that government sets the policy direction and the APS simply delivers (Grattan 2019; Morrison 2019; PM\&C 2019a, p. 9).

However, one relevant recommendation in the Independent review has been accepted: the establishment of a 'professions' model along the lines of what has been developed in the UK. The APS commissioner, Peter Woolcott, had already signalled that a formal professions model would be established to lift in-house skills and improve capability, looking to models in New Zealand, the UK and Singapore (Jenkins 2019a; PM\&C 2019 b, p. 20). A professions model for 'policy' might be expected to involve formal policy training with some academic input, whether in the form of accredited tertiary training, such as a masters degree, or short course offerings. Such formal teaching had been recommended both by

2 Heather Smith (the principal driver of the project), Mike Mrdak, Renée Leon and Kerri Hartland, who all spoke at the November launch, lost their positions under Morrison's restructure of the APS in December 2019 (Jenkins 2019b; Easton 2019b). 
academics and by other experts in the 2012 capability review conducted into the PM\&C (Crowley \& Head 2015, p. 7; Tiernan 2018). However, the practitioner-academic divide in Australian public policy remains a longstanding challenge, and one that may have been worsening 'to the detriment of both' (Stewart \& Buick 2019). The boundaries between what are seen as distinctly separate worlds, while not impermeable, entail different drivers, assumptions and expectations. John Wiseman (who inhabited both spaces at different times) has characterised the challenges to develop effective partnerships between these parallel universes as a case of 'dancing with strangers' (Wiseman 2010).

An essential context for this book is to understand this divide, sometimes referred to as 'two worlds' or 'two separate communities'. This includes understanding how the policy capacity of bureaucratic practitioners in Australia has been built primarily on learning by 'doing' and, correspondingly, how the academic field of policy studies is a relatively recent development in Australia and has been influenced by demands for practical policy analysis instruction for public servants. Our focus is specifically on bureaucratic policy practitioners, even though we recognise that there are many policy advisers outside the APS, both within ministerial offices and in many locations within the business sector, consultancy firms, community bodies and research centres. Broadening the analysis to include other such 'policy workers' may be work for future consideration.

\section{Terminology-different routes to the same destination?}

The 'two worlds' of theory and practice can have different terminology and, even more problematically, different meanings for the same terms. Because, as editors, we wanted the authors in this monograph to be able to approach their arguments in their own way, we did not impose a single or uniform nomenclature on contributors. Nonetheless, words matter and it is useful to briefly discuss key terms as they relate to this volume.

As Sabatier (2007, pp. 3-4) suggests, in seeking to understand or improve the practice of public policymaking, we inevitably simplify a highly complex, multifaceted reality. In the following chapters, much 
epistemological weight is carried by terms such as 'theory', 'model' and 'framework'. In general, a theory is contingent in character, providing a set of propositions that remain open to being disproved through empirical study; a model is more definitive and often aspires to be both empirically sound and normatively useful; while a framework is generally a looser construct of ideas and concepts that seeks to help understanding and guide action, without claiming unerring predictive power or perfect utility in all circumstances. In his text on public policy, Parsons (1995, pp. 57-61) presents a useful typology of policymaking 'frameworks', comprising three non-exclusive categories:

- explanatory frameworks, which seek to explain how policymaking happens, with a focus on causation, indicating expected pathways, given specific initial conditions

- 'ideal-type' frameworks, which classify types or forms of policymaking, using a variety of categorisation methods (e.g. policymaking as an expression of institutional and structural forms and norms)

- normative frameworks, which specify how policymaking ought to be done, given certain value preferences (e.g. analytical rigour, community engagement and political utility).

The distinctions and interactions between explanatory ('is') and normative ('ought') frames are especially important in this book. Practitioners and academics tend to fall somewhere on the continuum between these two poles; indeed, many are deeply concerned about the gap that can open up between how policymaking should proceed and how it is seen to actually play out in the real world. Perhaps a little paradoxically, many practitioners who venture into the theoretical literature seem to be idealistic or aspirational in their motivations, while many academics are more interested in the empirical evidence. Practitioners are often attracted to frameworks that are normative and ideal in character-for example, the Australian policy cycle or Moore's (1995) public value model-as touchstones for what their deeply pragmatic craft aspires to achieve. Many academics, on the other hand, are uneasy with loose frameworks that seem unreflective of what actually happens in real world policymaking, and they will often prefer more empirical or descriptive models, such as Charles Lindblom's (1959) 'muddling through' or John Kingdon's (2011) 
multiple streams approach. ${ }^{3}$ In this way, practitioners often use 'ought' to improve what 'is', while academics focus on analysing what 'is' to show where it falls short of what it 'ought' to be. Each are, perhaps, on different journeys towards if not the same destination, then to destinations that are closer than either group might imagine.

\section{Learning about policy 'on-the-job' - the infusion approach}

Practitioners well versed in policy theory are far from the norm. In the United States, a graduate recruited to undertake policy work for government organisations will, almost certainly, have undertaken accredited courses in public policy and government; however, a graduate recruited to the public sector in Australia is much less likely to have specific training in political science or government. Australian public servants principally learn their policy advising skills 'on-the-job', as do their counterparts in most Westminster countries (Allen \& Wanna 2016, pp. 27-8; Head 2015, p. 59). Among our contributors, both Kathleen Mackie and Andrew Maurer reflect on how their policy skills were built and honed through such 'learning by doing'-essentially an infusion approach after being 'thrown in the deep end'. These fundamental 'craft' skills for public servants are gradually acquired through practical learning, through knowledge passed on informally and through direct contact. These processes are also central to how public servants are inducted into the belief structures of their respective organisations, even if the doctrines are not explicitly articulated in detail (Rhodes 2016, p. 643; Rhodes \& Wanna 2009, pp. 158-9). While there is general consensus that policy skills are inculcated through this experiential process, there is very limited research into how such learning 'as you go' occurs (Adams, Colebatch \& Walker 2015, pp. 102-4).

3 Especially insofar as Kingdon builds on the 'garbage can' model outlined by Cohen, March and Olsen (1972). 
We do know, however, that academic policy training is subsidiary to this 'in-house' experiential training provided within the APS. This point is aptly illustrated in the recollections of Arthur Sinodinos, who joined the Department of Finance in 1979: ${ }^{4}$

While I'd had a certain amount of academic training in economics and commerce and all the rest of it, I really started to understand what you need to know when I became a public servant. I had to put that sort of training into operation. (Sinodinos 2017, p. 78)

The 70:20:10 pedagogic model developed by the APSC and adopted within many departments is built around this emphasis on unstructured and practical skills acquisition, with the 70 per cent coming from direct experiential learning, 20 per cent from relationships and networks and 10 per cent from formal education programs (Allen \& Wanna 2016, p. 28). Public service training in Australia and also New Zealand has indeed had a piecemeal history: fragmented training and development has been delivered mostly at the individual agency level with some external 'for credit' instruction supported for individual officers.

This emphasis on 'learning as you go' complements what is described as a characteristically Australian administrative trait of pragmatism, arguably linked to the pragmatism observed in the national political style (Edwards this volume, Chapter 7; Hollander \& Patapan 2007). Public servants attuned to the importance of practical experience and pragmatic action are therefore likely to be sceptical of theory-based learning and academic analysis. For some, this will be seen as floating in the stratosphere rather than a useful resource to be drawn on. This perception was conveyed by Peter Shergold (former APS 'mandarin' and also an accomplished academic) in his pithy description of public policy skill requirements as 'more in the nature of administrative craft and managerial mystery than political science' (Shergold 2015, p. xx).

In Australia, the various waves of NPM reform in the 1980s and 1990s produced the rise of performance-oriented 'managerialism' and the outsourcing of many traditional public service delivery programs. This was a period in which the public sector at all three levels of government were enjoined to undertake business and management training, with

4 Arthur Sinodinos was chief of staff to Prime Minister Howard between 1997 and 2006 and later became a New South Wales senator and government minister under prime ministers Abbott and Turnbull. 
accredited masters degrees in business administration becoming popular. The policy orientation of government was also being radically shifted by the rise of 'economic rationalism', with quantitative methods and economics qualifications becoming desirable skills for new graduates (Crowley \& Head 2015, p. 5). In Australia, those who acquired public policy training often did so at postgraduate level and not always in accredited training programs; it is not clear whether doing such studies was regarded as career enhancing by their agencies. In their survey of 55 state public servants in three capital cities, David Adams, Hal Colebatch and Christopher Walker (2015, p. 81) found that only half reported any previous formal study of policy, and those who were enrolled in policyrelated studies had done so at their own initiative. At the Commonwealth level, the Rudd government's Ahead of the game report in 2010 found serious underinvestment by the APS in staff development (Advisory Group on Reform of Australian Government Administration 2010, pp. viii-ix). The APS policy capability roadmap released in March 2019 reported that foundational training, while provided by many agencies, was targeted at graduates, and that policy advisory staff generally had to 'go it alone' on professional development (Australian Government 2019, p. 14).

\section{Learning about policy in the 'ivory towers'-academic and applied approaches}

The APS policy capability roadmap reported that policy advisers were critical of the relevance and 'fit' of training provided by academics and consultants (Australian Government 2019, p. 14). However, Michael Di Francesco (2015, p. 261) has shown that the field of policy analysis instruction in Australia (mainly termed 'public policy') has been 'firmly grounded in an Antipodean proclivity towards pragmatism'. As both an academic and a practitioner field, it encompasses both the academic analysis of policy (to explain decisions and their making) and the applied focus of analysis for policy (to improve decisions) (Di Francesco 2015, pp. 261-2). This marks a critical point of difference with the United States and Canada, where the nexus between theory and practice is reflected in the professional affiliation of most universities and schools that teach policy with a formal accreditation system incorporating standards for policy programs and a core curriculum for 'professional degrees'. 
In Australia, public policy as a university-level field of study within the umbrella of political science is now well established and its growth has seen a corresponding decline in 'public administration' course offerings (Crowley \& Head 2015, p. 5). Di Francesco's (2015, p. 270) extensive survey of current structures and programs for public policy in Australia located 18 instances of public policy programs offered in the 41 Australian university-level institutions, including five entities that were classified as standalone 'policy schools'. One of these is the Australia and New Zealand School of Government (ANZSOG), established in 2002 by the Commonwealth and several state governments and New Zealand. It is seen as a dedicated school for building executive capacity-a unique experiment that is the focus of John Wanna's case study in this book.

The growth in policy analysis studies has been linked to the relatively recent expansion in government and individual demand for policy training (Di Francesco 2015, p. 277), of which ANZSOG is the leading organisational example of tailored training. While there is no standard core curriculum in this field across Australian and New Zealand universities, Di Francesco's survey indicated that across both undergraduate and postgraduate levels, some commonalities included standalone subjects on policy theory and public policy, and an emphasis on examining case studies on sectoral policy or public policy process (Di Francesco 2015, pp. 274-5). The use of teaching cases has been taken to a new level within ANZSOG, including the use of case teaching in its two signature programs, the Executive Masters of Public Administration and the condensed Executive Fellows Program.

Policy studies have also morphed into other academic disciplines and fields of inquiry in universities. These tend to be more sectoral in application but still very focused on policy development and implementation. These areas include environmental and climate change policy, water and drought policy, human rights policy, national security policy, demographic and immigration policy, Indigenous policy, health and educational policy, and foreign aid policy etc. Most of these sectoral areas investigate policy options rather than policymaking per se, but may work from disciplinary specific approaches to policymaking.

Exactly what policy theories are offered through the more generic tertiary courses on public policy has not been well documented. However, since the late 1990s, the policy theories offered both through university institutions and also through major textbooks has generated vigorous 
debate within Australia, especially regarding two particular theories. One is the 'Australian policy cycle'-a modified version of the classic stages or cycle approach originating in North American discussions in the 1960s. It was expounded in a popular textbook, The Australian policy handbook, first published in 1998 by Peter Bridgman and Glyn Davis (based on a 1995-96 Griffith University consultancy on policy formulation for the Queensland Government) and now in its sixth edition (Althaus, Bridgman \& Davis 2018). This policy cycle model is offered as a 'good process' guide for public servants and the associated handbook is a classic text for both undergraduate policy subjects and graduate courses (Di Francesco 2015, p. 267). Critiqued as an attractive but unrealistic theory of the policy development process (Adams, Colebatch \& Walker 2015, p. 108; Gill \& Colebatch 2006, pp. 261-2), the Australian policy cycle's perceived strength is its practical approach and comprehensiveness in capturing the entirety of policy development and implementation activities. Its utility is explored extensively in the chapters by Russell Ayres, Meredith Edwards and Trish Mercer in this volume. Institutionally, as Andrew Maurer's contribution demonstrates, such a stages approach continues to hold attraction as a means of underlining the sequence of actions underpinning 'good' policy development. Gary Banks (2018), former head of the Productivity Commission and a supporter of 'an ordered approach' to policymaking, describes the steps in the cycle as differing little from those set out in the regulatory assessment requirements that apply in all Australian jurisdictions. Yet, as the policy theorist Cairney (this volume, Chapter 13) argues, this theory of policy made from the centre via a series of logical stages entails a much too simple understanding of policy processes compared to the far messier realities of a complex system over which policy practitioners have little control.

The second contentious public policy theory is the 'public value' approach for strategic public management associated with Mark Moore from Harvard's Kennedy School of Government. This approach articulates a strategic triangle framework offering three tests of a public policy: whether it is valuable, legitimate and doable (Moore 1995). As a heuristic, the public value approach with these three criteria has been taken up with gusto by public managers, and has achieved wide circulation through being embedded in core elements of ANZSOG's higher level training curriculum (Alford \& O'Flynn 2009, pp. 171-2). Whether public value is appropriate within Westminster systems, with their focus on ministerial leadership and public service responsiveness to governmental priorities, 
has been the subject of robust debate (Alford 2008; Alford \& O'Flynn 2009; Bryson, Crosby \& Bloomberg 2014; Rhodes \& Wanna 2007, $2008,2009)$. A recent workshop on understanding public value explored the ambiguities of the concept, noting the wide variety of ideas about where public value is created and by whom. Nevertheless, the concept has resonance for public servants demonstrated through its extensive application:

Public value ... was a term created by academics and then adopted by public managers, a cycle of ideas in which academics try to describe what practitioners do and then practitioners use to describe their work. (Brown et al. 2019, p. 21)

As Di Francesco (2015, p. 268, original emphasis) remarks, these debates are emblematic in drawing attention to the apparent gap between academic and practitioner knowledge about policy: 'the nub of the dispute is that practitioners find the concept [of public value] useful'. This is manifested, as Mercer's chapter illustrates, in the willingness of many senior public servants to reference Moore's authorising environment when discussing public policy in external forums. Indeed, in the APS policy capability roadmap, a strong authorising environment is posited as a key area of focus to increase the demand for good practice policy development (Australian Government 2019, p. 20; Mercer this volume, Chapter 3). Both of these policy theories, and the debates they have engendered, are explored in several of our chapters, along with another influential policy theoryJohn Kingdon's (2011) multiple streams approach. This approach, while essentially setting out to explain how the United States Congress makes policy decisions (within a highly entrepreneurial political system and lower party discipline), has been applied in numerous empirical studies (including on parliamentary systems), although sometimes superficially (Cairney \& Jones 2016, p. 38).

An associated area of strong academic and practitioner interest in Australasia has been the theoretical exploration of the contested area of policy success and failure. In particular, Allan McConnell (2015, pp. 232-6), also a contributor in this book, has explored methodological difficulties in analysing the maze of what constitutes success or failure, and developed a framework to map the characteristics of different policy outcomes in terms of three analytical categories: process, program, and political success or failure. He underlines the importance of engaging with the real world complexities—-the realpolitik—of policy failure: 
We need to accept that failure is bound up with issues of politics and power, including contested views about its existence, and the power to produce an authoritative and accepted failure narrative.

Mackie, as a practitioner academic, relates in her chapter how she employed McConnell and Marsh's 2010 framework as a useful rubric to analyse 12 policy episodes of environmental policymaking, including the Rudd government's Home Insulation Program, which was the subject of a scathing Royal Commission report commissioned by the succeeding Abbott Coalition government. Mackie's intention was to determine which episodes could be categorised as a policy 'success' or 'failure'. Luetjens, Mintrom and 't Hart's (2019b, pp. 3, 7) study, which aims to reset the agenda for teaching, research and dialogue on public policy performance and success in Australia and New Zealand, adopts McConnell's success framework, with the addition of a fourth, temporal dimension that assesses success over time.

\section{The purpose of this book}

Those engaged in policy practice are, then, increasingly being offered policy theory through formal and informal training, and through textbooks and published research. Yet, we have little empirical evidence as to the impact of such policy theory on the individuals or their workplaces. While the Commonwealth's policy capability project has estimated that there are more than 7,000 'policy advisers' in the APS (Australian Government 2019, p. 1), the potential audience for theory-informed practice extends also into public servants involved in service and program delivery, regulation and compliance, given the interconnection between policy design and implementation and monitoring.

This book aims to begin to address this gap in our evidence base by bringing together insights from research, teaching and practice on the relationship between theory and policy practice. Its impetus came from an ANZSOG workshop held in Canberra in July 2018 organised by Trish Mercer and John Wanna with Brian Head's assistance, in order to open the conversation about theory-informed practice. $^{5}$ The diverse audience

5 The workshop, 'Building communities of practice: exploring how practitioners access and respond to academic policy frameworks', was held at The Australian National University on 9 July 2018. Some of the contributors to this book (Ayres, Althaus, Threlfall, Gilding, Mackie and Mercer) were presenters at the workshop. 
of Australian and New Zealand academics, practitioner academics and public servants from the national and capital territory jurisdictions were enthusiastic about the opportunity to hear academic and practitioner presentations on the theory-practice nexus. They were keen to share insights about what we know-and, more often, what we do not knowabout 'making theory speak to practice', as David Threlfall and Catherine Althaus subtitled their workshop presentation. A subsequent ANZSOG sponsored visit to Australia and New Zealand in October 2018 by Paul Cairney explored inter alia how we can take lessons from policy theory into practice, including for evidence-based policymaking.

Given the interest expressed at the July 2018 workshop, an editorial committee was formed of Head, Mercer and Wanna, joined by one of the practitioner academic presenters at the October 2018 workshop, Russell Ayres. We have deliberately sought to bring together contributions from the academy with those from former or current public servants to ground this work in the practical experience of real world policy.

To explore how policy theory is transferred and taken into practice, we decided to seek contributions under three broad headings:

1. outlining the landscape for policy training and identifying gaps in our knowledge of how theory and practice have influenced each other in the Australian and also international contexts

2. exploring how current and former practitioners have employed policymaking theory to support their analysis of policy episodes and/or as a sense-making tool for themselves and the people with whom they work

3. tapping into the latest research on how lessons can be taken from policy theory into practice.

These three topics became the basis for the three parts of the volume. The core questions explored by our contributors can be summarised thus:

- How is policy training offered in Australia and what are the challenges?

- What can we uncover about which policy theories have been influential (and why) among practitioners? What is the role of heuristics in reflective policy learning?

- Is the divide between the worlds of academia and policy practice as significant as the literature suggests? 
- How have individual practitioners, including practitioner academics, employed — and adapted — policy theory, either for analytical purposes of studying past policy episodes or for their own and their teams' reflective learning?

- How do institutions seek to connect theory and practice implicitly or explicitly?

- How can policy theorists offer insights in a form and through a medium that is relevant and useful for those engaged in policy practice?

Our analytical gaze falls primarily on investigating whether policy theory can speak to practice. However, one of the questions generated through this book, and particularly by Threlfall and Althaus, Mackie and also Cairney, is how we can move towards practice-influenced theory. This is a seminal question for a future research agenda — one that fundamentally addresses the interconnectivity between practice and theory.

This work was completed before the major changes in the operational routines of governments, universities and corporate organisations catalysed by the national and global response to the COVID-19 pandemic. We have not attempted to forecast the possible impacts on working relationships and lessons for dealing with rapidly changing challenges that this crisis has produced. Indeed, the experience of balancing health and economic impacts in a highly uncertain environment and preparing for the aftermath may well change both the practice of policymaking and how it is theorised. However, policy theorists have been quick to offer insights and perspectives for practitioners endeavouring to develop public policy responses to this unprecedented global crisis and to learn from the experience of other governments, including through ANZSOG's 'Leading in a crisis' series of online articles (Macpherson \& 't Hart 2020; McConnell, Stern \& Boin 2020; Weible et al. 2020).

\section{Overview of the book}

This book is addressed to practitioners and academics alike. We see this as an opportunity to open up discussion on this all too hidden area: practitioners rarely volunteer information on how they employ and adapt theory in their policymaking experiences, and academics are more often preoccupied with developing than with offering theory to those involved in policy 'doing'. We seek to investigate this area by structuring our contributions in three parts. 
Part 1 examines theorising, teaching and learning about policymaking, drawing on not only academic perspectives but also practitioner academics who bring their knowledge of how theory can translate at the level of policy workers. It explores:

- whether the emphasis on a theory-practice divide obscures the interconnection between these two communities

- what we can discover about how public servants acquire their policy knowledge and skills, and the role played by academic training in building capacity, particularly through the Antipodean experiment of ANZSOG

- what policy theories have been offered, or could be offered, to public servants across all areas of government, including parliament, and what we can discover about the resonance and translation of such theory for policy practitioners.

Part 2 provides access into the insider world of current and former practitioners who bring insights seldom available to academics about their interactions with the processes, documents and relationships that move policy forward. It explores:

- how theory can be applied to offer insights for practical action, and the processes of simplification and distillation that play out in such adaptations

- which theories have been found to offer coherent frameworks (i.e. to strike a chord) and in what circumstances

- whether theories can be adapted by blending or by mixing and matching them to provide greater applicability, and how policymakers might go about this

- whether theory can be employed at an institutional level, and how it is influenced by the culture and environment of a public service agency.

Part 3 examines how theory can better inform practice and vice versa. Two policy theorists offer their perspectives on how policy theory can indeed assist policy practitioners by examining:

- how insights from policy theory can help policy practitioners understand the complex nature of the policy process that they themselves observe and in which they are immersed

- how theories can offer a way of thinking to help set up a new agenda to consider how policy should be made 
- the importance of having realistic expectations of what is possible in the worlds of both academic theory and policy practice and avoiding stereotypes of these, and of exploring opportunities for interaction and shared space.

As this structure indicates, our contributors represent the views of a spectrum of writers, from those whose days are spent thinking about policymaking to those who are engaged in the business of fast-paced policy decision-making and implementation to those who inhabit the worlds in-between: policy analysts, public policy researchers and academics, public policy teachers, policy consultants, policy practitioners, and some who juggle more than one of these roles or have worked across the 'two communities'. We see this plurality and diversity as a particular strength of the monograph.

\section{Our chapters and contributors}

The rest of Part 1 explores theorising, teaching and learning about policymaking. Chapter 2, by David Threlfall and Catherine Althaus, both of whom have academic and practitioner experience, interrogates the relationship and interconnection between theory and practice and the fundamental role of heuristics in reflective policy learning. In Chapter 3, Trish Mercer, a former APS senior executive and now an ANZSOG visiting fellow, examines the impact of academic theories about policymaking, focusing on four specific theories that traverse the theory spectrum to investigate which have resonated with Australian public servants and why. John Wanna draws on his ANZSOG research and teaching experience in Chapter 4 to explore the issues and challenges (including in offering policy theory concepts) associated with teaching public policy through senior executive education programs and, in particular, through ANZSOG's key programs.

In Chapter 5, New Zealand-based researchers Karl Löfgren and Sarah Hendrica Bickerton consider the concept of two separate communities of theory and practice and, based on their survey into how policy professionals in New Zealand use academic research, conclude that the picture is more complex and dispersed than generally perceived. With the lens of a former parliamentary senior manager, Val Barrett, in Chapter 6, 
draws on her research into Australia and the UK's national parliaments to argue that the characteristics of public value are as appropriate for parliamentary administration as they are for public administration.

Part 2, as indicated above, delves further into the world of practice seen through a theory lens with contributions by practitioners and practitioner academics. Some have employed policy theory within their workplaces whereas others have employed theory to analyse and reflect on policy episodes or to investigate policymaking as a cross-cultural endeavour. In Chapters 7 and 8, our contributors offer different reflections on their public service careers through the prism of the policy cycle. As one of the 'boundary riders' between the public service and academia, Meredith Edwards puts the policy cycle in a practical context in her reflections on Australia's public policy processes. Russell Ayres describes how his professional practice as a senior APS executive (2004-16) was informed by his academic knowledge of policymaking theory and research, and how he employed his theoretical insights to offer his staff a way of seeing policy through the policy cycle admixed with observed practice.

Assessing success and failure in environment policy through the lens of policy theory was the subject of Kathleen Mackie's doctoral research. Drawing on her interviews with key policy practitioners in the Commonwealth department, assisted by her previous experience as a departmental senior executive, Mackie highlights the significance of the agency exerted by officials as a key to understanding policy success and failure in Chapter 9. In the next chapter, Craig Ritchie, head of a key Aboriginal and Torres Strait Islander cultural and research agency, critiques our reflexively rationalist, Western Enlightenment-inspired approach to policymaking. He argues that this approach leads to mental shortcuts and assumptions that all but guarantee failure when dealing with the deeply different ways of seeing and being manifest among Aboriginal and Torres Strait Islander cultures.

Louise Gilding offers insights into her theory-informed practice as a senior executive in the Australian Capital Territory Government in Chapter 11. Drawing on the public value theory featured in her ANZSOG masters study, she describes the 'blended approach' she employs with her teams and for her own analytical and reflective purposes. In Chapter 12, the final chapter in Part 2, we see how Andrew Maurer employed the rational-comprehensive approach of the policy cycle as an overarching template to develop a policy handbook while working as a senior executive 
in the then Australian Department of Communications and the Arts. During its development, this 'in-house' guide would come to map the complementary roles of the department's new organisational structure and provide a common language and heuristic guide.

Part 3 presents insights from two leading public policy theorists on the processes underpinning policymaking in the modern state. UKbased theorist Paul Cairney, whose textbooks, blogs and research into policy theory reach an international audience, argues in Chapter 13 that policymakers and practitioners could utilise insights from policy theories if they were communicated more effectively, and that these insights could be used to explore common constraints and ethical dilemmas. In Chapter 14, Allan McConnell, a public policy specialist, synthesises the various authors' contributions, addressing the need for realistic expectations about what academic theory can bring, the dangers of stereotyping the two 'separate' worlds, the potential benefits of sharing the same space and the value of looking beyond the tip of the academic iceberg.

The concluding chapter explores why, and to whom, the debate about policy capacities and skills is important; the contours of the debate; the range of policy skills and practices involved; and future directions for applied research, including how theory can be tested against practice. We end, we hope, by offering something for practitioners looking for ways to improve their craft, academics keen to see future opportunities for applied research, and academic and practitioner partners who want the best of both worlds.

\section{References}

Adams, D, Colebatch, HK \& Walker, CK 2015, 'Learning about learning: Discovering the work of policy', Australian Journal of Public Administration, vol. 74, no. 2, pp. 101-11, doi.org/10.1111/1467-8500.12119.

Advisory Group on Reform of Australian Government Administration 2010, Ahead of the game: Blueprint for the reform of Australian government administration, Department of the Prime Minister and Cabinet, Canberra, ACT.

Alford, J 2008, 'The limits to traditional public administration, or rescuing public value from misrepresentation', Australian Journal of Public Administration, vol. 67, no. 3, pp. 357-66, doi.org/10.1111/j.1467-8500.2008.00593.x. 
Alford, J \& O’Flynn, J 2009, 'Making sense of public value: Concepts, critiques and emergent meanings'. International Journal of Public Administration, vol. 32, nos. 3-4, pp. 171-91, doi.org/10.1080/01900690902732731.

Allen, P \& Wanna, J 2016, 'Developing leadership and building executive capacity in the Australian public services for better governance', in A Podger \& J Wanna (eds), Sharpening the sword of state: Building executive capacities in the public services of the Asia-Pacific, ANU Press, Canberra, ACT, doi.org/ 10.22459/SSS.11.2016.02.

Althaus, C, Bridgman, P \& Davis, G 2018, The Australian policy handbook: A practical guide to the policy-making process, 6th edn, Allen \& Unwin, Crows Nest, NSW.

Australian Government 2013, Australian Public Service Commission state of the service report 2012-13, Canberra, ACT.

Australian Government 2019, APS policy capability roadmap: A practical plan to lift policy capability across the APS, viewed 16 April 2020, www.policyhub.gov.au/ sites/default/files/projects/aps-policy-capability-roadmap.pdf.

Banks, G 2018, 'Whatever happened to “evidence based policy making?"', Alf Rattigan Lecture delivered 20 November, Canberra, ACT, viewed 16 April 2020, apo.org.au/node/206646.

Brown, P, Cherney, L, Warner, S with Ugochie CA, Ball, S, Cunningham, LE, Le, LDD, Simpson Reeves, L \& Worsoe, H 2019, Understanding public value workshop: Report on proceedings, University of Queensland, viewed 16 April 2020, polsis.uq.edu.au/files/22013/understandingpublicvalueworkshopreport corrected.pdf.pdf.

Bryson, JM, Crosby, BC \& Bloomberg, L 2014, 'Public value governance: Moving beyond traditional public administration and the new public management', Public Administration Review, vol. 74, no. 4, pp. 445-56, doi.org/10.1111/ puar. 12238.

Cairney, P 2015, 'How can policy theory have an impact on policymaking? The role of theory-led academic-practitioner discussions', Teaching Public Administration, vol. 33, no. 1, pp. 22-39, doi.org/10.1177/0144739414532284.

Cairney, P 2020, Understanding public policy theories and issues, 2nd edn, Red Globe Press, London, UK.

Cairney, P \& Jones, MD 2016, 'Kingdon's multiple streams approach: What is the empirical impact of this universal theory?', Policy Studies Journal, vol. 44, no. 1, pp. 37-58, doi.org/10.1111/psj.12111. 
Cairney, P \& Weible, C 2017, 'The new policy sciences: Combining the cognitive science of choice, multiple theories of context, and basic and applied analysis', Policy Sciences, vol. 50, no. 4, pp. 619-27, doi.org/10.1007/s11077-0179304-2.

Cohen, M, March, J \& Olsen, J 1972, 'A garbage can model of organisational choice', Administrative Science Quarterly, vol. 17, no. 1, pp. 1-25, doi.org/ $10.2307 / 2392088$.

Commonwealth of Australia 2019, APS Review: Priorities for change, Department of the Prime Minister and Cabinet, viewed 16 April 2020, www.apsreview.gov. $\mathrm{au} /$ resources/priorities-change.

Crowley, K \& Head, B 2015, 'Policy analysis in Australia: Context, themes and challenges', in B Head \& K Crowley (eds), Policy analysis in Australia, Policy Press, Bristol, UK, doi.org/10.1332/policypress/9781447310273.003.0001.

Daniell, K \& Kay, A (eds) 2017, Multi-level governance: Conceptual challenges and case studies from Australia, ANU Press, Canberra, ACT, doi.org/10.22459/MG. 11.2017.

Department of the Prime Minister and Cabinet (PM\&C) 2019a, Delivering for Australians, viewed 5 February 2020, pmc.gov.au/resource-centre/ government/delivering-for-australians.

Department of the Prime Minister and Cabinet (PM\&C) 2019b, Our public service, our future. Independent review of the Australian Public Service, viewed 5 February 2020, pmc.gov.au/sites/default/files/publications/independentreview-aps.pdf.

Di Francesco, M 2015, 'Policy analysis instruction in Australia', in B Head \& K Crowley (eds), Policy analysis in Australia. Policy Press, Bristol, UK, doi.org/10.1332/policypress/9781447310273.003.0017.

Easton, S 2019a, 'APS secretaries unveil online collaboration hub in push to improve policy skills', Mandarin, 21 June, viewed 16 April 2020, www.themandarin. com.au/110225-aps-secretaries-unveil-new-online-collaboration-hub-in-pushto-improve-policy-skills/.

Easton, S 2019b, 'Four departments and five secretaries cut while one returns, as PM reshapes the public service', Mandarin, 5 December, viewed 16 April 2020, www.themandarin.com.au/122170-from-the-desk-of-the-prime-ministerhere-is-your-new-public-service/.

Gill, Z \& Colebatch, HK 2006, 'Busy little workers': Policy workers' own accounts', in HK Colebatch (ed.), Beyond the policy cycle: The policy process in Australia, Allen \& Unwin, Crows Nest, NSW. 
Grattan, M 2019, 'View from The Hill: Morrison won't have a bar of public service intrusions on government's power', Conversation, 13 December, viewed 16 April 2020, theconversation.com/view-from-the-hill-morrison-wont-havea-bar-of-public-service-intrusions-on-governments-power- 128880 .

Head, B 2015, 'Policy analysis and public sector capacity', in B Head \& K Crowley (eds), Policy analysis in Australia, Policy Press, Bristol, UK, doi.org/10.1332/ policypress/9781447310273.001.0001.

Hollander, R \& Patapan, H 2007, 'Pragmatic federalism: Australian federalism from Hawke to Howard', Australian Journal of Public Administration, vol. 66, no. 3, pp. 280-97, doi.org/10.1111/j.1467-8500.2007.00542.x.

Jenkins, S 2019a, 'This APS review will be different, says Commissioner', Mandarin, 26 September, viewed 16 April 2020, www.themandarin.com.au/ 116772-this-aps-review-will-be-different-says-commissioner/.

Jenkins, S 2019b, 'How to deliver great policy advice', Mandarin, 5 December, viewed 16 April 2020, www.themandarin.com.au/122114-how-to-delivergreat-policy-advice/.

Kingdon, JW 2011, Agendas, alternatives, and public policies, updated 2nd edn, Longman, Crawfordsville, IN.

Lindblom, CE 1959, 'The science of "muddling through"', Public Administration Review, vol. 19, no. 2, pp. 79-88, doi.org/10.2307/973677.

Lindquist, E 2010, 'From rhetoric to blueprint: The Moran review as a concerted, comprehensive and emergent strategy for public service reform', Australian Journal of Public Administration, vol. 69, no. 2, pp. 115-51, doi.org/10.1111/ j.1467-8500.2010.00684.x.

Luetjens, J, Mintrom, M \& 't Hart, P 2019a, Successful public policy: Lessons from Australia and New Zealand. ANU Press, Canberra, ACT, doi.org/10.22459/ SPP.2019.

Luetjens, J, Mintrom, M \& 't Hart, P 2019b, 'On studying policy successes in Australia and New Zealand', in J Luetjens, M Mintrom, \& P 't Hart (eds), Successful public policy: Lessons from Australia and New Zealand, ANU Press, Canberra, ACT, doi.org/10.22459/SPP.2019.01.

Macpherson, R \& 't Hart, P 2020, 'Leading in a crisis: Using adaptive leadership to shape the COVID-19 crisis response', ANZSOG, 18 April, viewed 23 April 2020, www.anzsog.edu.au/resource-library/research/using-adaptiveleadership-to-shape-the-covid19-crisis-response. 
McConnell, A 2015, 'What is policy failure? A primer to help navigate the maze', Public Policy and Administration, vol. 30, nos 3-4, pp. 221-42, doi.org/ 10.1177/0952076714565416.

McConnell, A, Stern, EK \& Boin, A 2020, 'Leading in a crisis: How to learn from others', ANZSOG, 28 April, viewed 3 May 2020, www.anzsog.edu.au/ resource-library/research/how-to-learn-from-others.

Moore, MH 1995, Creating public value: Strategic management in government, Harvard University Press, Cambridge, MA.

Morrison, S 2019, 'Prime Minister's address to the Australian Public Service', 19 August, Institute of Public Administration Australia ACT Division, viewed 16 April 2020, www.act.ipaa.org.au/2019-pastevent-primeminister.

Nature Neuroscience 2005, '(Editorial) The practice of theoretical neuroscience', Editorial Nature Neuroscience, vol. 8, no. 12, p. 1627, doi.org/10.1038/ nn1205-1627.

O'Flynn, J, Vardon, S, Yeatman, A \& Carson, L 2011, 'Perspectives on the capacity of the Australian Public Service and effective policy development and implementation', Australian Journal of Public Administration, vol. 70, no. 3, pp. 309-17, doi.org/10.1111/j.1467-8500.2011.00731.x.

Parsons, W 1995, Public policy: An introduction to the theory and practice of policy analysis. Edward Elgar, Cheltenham, UK.

Parsons, W 2004, 'Not just steering but weaving: Relevant knowledge and the craft of building policy capacity and coherence', Australian Journal of Public Administration, vol. 63, no. 1, pp. 43-57, doi.org/10.1111/j.14678500.2004.00358.x.

Rhodes, RAW 2016, 'Recovering the craft of public administration', Public Administration Review, vol. 76, no. 4, 638-47, doi.org/10.1111/puar.12504.

Rhodes, RAW \& Wanna, J 2007, 'The limits to public value, or rescuing responsible government from the platonic guardians', Australian Journal of Public Administration, vol. 66, no. 4, pp. 406-21, doi.org/10.1111/j.14678500.2007.00553.x.

Rhodes, RAW \& Wanna, J 2008, 'Stairways to heaven: A reply to Alford', Australian Journal of Public Administration, vol. 67, no. 3, pp. 367-70, doi.org/10.1111/ j.1467-8500.2008.00594.x.

Rhodes, RAW \& Wanna, J 2009, 'Bringing the politics back in: Public value in Westminster parliamentary government', Public Administration, vol. 87, no. 2, pp. 161-83, doi.org/10.1111/j.1467-9299.2009.01763.x. 
Sabatier, PA 2007, 'The need for better theories', in PA Sabatier (ed.), Theories of the policy process, Westview Press, Boulder, CO.

Shergold, P 2015, 'Foreword', in B Head \& K Crowley (eds), Policy analysis in Australia, Policy Press, Bristol, UK.

Sinodinos, A 2017, 'Innovations awards address', in IPAA speeches 2017. A year of speeches from public service leaders, Institute of Public Administration Australia ACT Division, Canberra, ACT.

Stewart, J \& Buick, F 2019, 'The academic-practitioner divide in public management: and how to bridge it', Power to Persuade, blog 6 June, viewed 16 April 2020, www.powertopersuade.org.au/blog/the-academic-practitionerdivide-in-public-management-and-how-to-bridge-it/6/6/2019.

Tiernan, A 2011, 'Advising Australian federal governments: Assessing the evolving capacity and role of the Australian Public Service', Australian Journal of Public Administration, vol. 70, no. 4, pp. 335-46, doi.org/10.1111/j.14678500.2011.00742.x.

Tiernan, A 2018, 'Public sector capability. Buy it or build it?', PolicyInnoHub, 20 March, viewed 20 April 2020, medium.com/the-machinery-of-government/ public-sector-capability-f4a40fe38739.

Weible, CM, Nohrstedt, D, Cairney, P, Carter, DP, Crow, DA, Durnova, AP, Heikkila, T, Ingold, K, McConnell, A \& Stone, D 2020, 'COVID-19 and the policy sciences: Initial reactions and perspectives', Policy Sciences, vol. 53, no. 2, pp. 225-41, doi.org/10.1007/s11077-020-09381-4.

Weible, CM \& Sabatier, PA 2017, Theories of the policy process, 4th edn, Westview Press, Boulder, CO.

Wiseman, J 2010, 'Dancing with strangers: Understanding the parallel universes of academic researchers and public sector policy makers', ANZSOG Occasional Paper No. 11, Victorian State Services Authority and ANZSOG. 
This text is taken from Learning Policy, Doing Policy: Interactions Between Public Policy Theory, Practice and Teaching, edited by Trish Mercer, Russell Ayres, Brian Head and John Wanna, published 2021 by ANU Press, The Australian National University, Canberra, Australia.

doi.org/10.22459/LPDP.2021.01 